\title{
Radiofrequency Electromagnetic Fields: Carcinogenic and Other Biological Effects
}

\author{
Sergei V. Jargin ${ }^{1, *}$ \\ ${ }^{1}$ Department of Public Health, Peoples' Friendship University of Russia, Mos- \\ cow, Russia \\ *Corresponding author: Sergei V. Jargin, Department of Public Health, \\ Peoples' Friendship University of Russia, 117198 Moscow, Russia. Tel: \\ +74959516788; Fax: +74959516788; E-mail: sjargin@mail.ru
}

DOI: 10.30699 /acadpub.mci.3.2.5

Submitted: 13 February 2019

Revised: 2 March 2019

Accepted: 19 March 2019

e-Published: 1 April 2019

\section{Keywords:}

Electromagnetic Fields

Cell Phone

Neoplasms

\begin{abstract}
In the electromagnetic spectrum, structural damage to living tissues per unit of absorbed energy tends to increase with the decrease of a wavelength which is evident not only for ultraviolet and ionizing radiation but also for the infrared and visible light. By causing thermal damage after absorbing energies that would be harmless for radiofrequency electromagnetic fields (EMF), tissues are evenly heated. There are no prima facie reasons to expect more damage from EMF than from infrared radiation which is believed to be harmless in terms of thermal damage. Several studies reported possible associations between EMF, glioma and other tumors. Other research did not confirm such associations or even identified a reduced risk of brain tumors among mobile phone (MP) users. An elevation in the application of MP has been observed in some countries and age groups which is out of proportion. Improving imaging technology and access to health care units have contributed to an increased incidence rate. Bias is known to occur in epidemiologic research. At the beginning of the MP era, the use of MP was associated with a high income which, in turn, must be associated with better diagnostics results. Admittedly, nowadays MPs are affordable for the majority of people and it is unclear whether the socioeconomic bias still plays a significant role. In conclusion, there is neither compelling evidence nor theoretic plausibility for the concept that EMF is more harmful than infrared radiation per unit of absorbed energy.
\end{abstract}

(C) 2019. Multidisciplinary Cancer Investigation

\section{INTRODUCTION}

This mini-review attempts to apply the concept of hormesis to radiofrequency electromagnetic fields (EMF), which was previously performed for ionizing radiation [1]. Hormesis describes biphasic dose-response processes to increasing doses of a substance or condition; typically, low doses induce a beneficial response; while higher doses cause harm [2]. Hormesis can be generally explained by the evolutionary adaptation to a current level of an environmental factor or to some average from the past. The natural background EMF was probably

higher in the past, so that living organisms may have retained some adaptation to higher EMF levels than today's natural background. It is known that EMF is partly reflected and attenuated by the ionosphere. Ionized oxygen is one of the main components of the ionosphere [3]. It can be reasonably assumed that oxygen accumulation in the atmosphere is contributed to a decrease of the EMF background on the Earth surface due to the photosynthesis. In any case, considering fluctuations of the solar activity and atmospheric electricity, the adaptation 
of living organisms to EMF has probably occurred in a broad range. There is some in vivo and in vitro experimental evidence of hormetic responses to EMF [4-7].

\section{Biophysical Aspects}

In the range of EMF frequencies, the structural damage of living tissues per unit of absorbed energy tends to increase with the decreasing wavelength. the structural damage is caused both by ultraviolet and ionizing radiation as well as infrared and visible light. After being absorbed in superficial tissue layers, thermal damage is caused that would be harmless for EMF; while tissues are evenly heated. Accordingly, there are no prima facie reasons to anticipate more important damages from EMF than from infrared radiation which is believed to be harmless in terms of thermal damage. Apart from EMF, a body can be heated by thermal conduction e.g. from surrounding hot air or water. If the absorbed energy is assumed to be equal, a hot bath can cause more structural damage (if any) than EMF. Heating by conduction means an intensification of thermal or Brownian motion of all molecules including potentially vulnerable nucleic acids and proteins. EMF generates currents with the movement primarily of charged or polar particles such as ions and water molecules $[8,9]$. Indeed, an increased risk of malignancy and DNA break repair inhibition after multiple heat exposures have been reported [10-12]. In daily life, EMF is rarely intensive enough to cause measurable heating of a human body. There is no reliable evidence of molecular or other structural alteration caused by being heated with thermal conduction, infrared or radiofrequency radiation which means that they are all below the level of thermal damage. The evidence for genotoxic effects of EMF is considered to be very weak [13]. In this regards, a hypothesis about oxidative stress as a supposed mechanism of harmful EMF effects should be mentioned [14-16], as there are no clear reasons to assume that EMF causes more oxidative stress than infrared rays or heating by conduction. The concept of oxidative stress seems to be generally overused $[17,18]$.

The specific energy absorption rate (SAR) per unit of tissue mass $(\mathrm{W} / \mathrm{kg})$ is the main measure of exposure to EMF. SAR values are usually averaged over time, either over the periodicity of the signal or over any period of 6 minutes. The relationship between SAR and tissue temperature depends on thermophysiological parameters, especially blood perfusion rates $[9,19,20]$. The only consistent proven biological effect of EMF in humans is heating. Some discussed effects as non-thermal may be thermal in nature, while subtle thermal effects from EMF usually have no consequence to health [21-23]. Accordingly, the goal of SAR restrictions/limits in guidelines and standards is the prevention of whole-body heat stress and excessive local temperature rise. The heating of brain tissue is most relevant for mobile phone (MP) users for which adults and children head models are used in scientific research $[9,19,20,24]$. In future, potential damaging hot spots due to focally enhanced tissue by conduction and/or wave interference in a motionless target should be studied in models imitating an extreme situation such as a child sleeping with an emitting MP at his or her ear [25].

\section{Epidemiological Research}

According to the International Agency for Research on Cancer (IARC), there is limited evidence in favor of carcinogenicity of EMF, although they have also declared an alternative opinion that the evidence in humans is inadequate $[9,26]$. Several epidemiological studies reported associations between EMF and glioma, acoustic neuroma, and other tumors [27-36]. Other research did not confirm such associations or even identified a diminished risk of brain tumors among MP users [37-42], which could have been caused by bias and/or hormesis. In the large multicenter INTERPHONE study, no increase in the risk of glioma or meningioma was observed in MP users. There were suggestions of an elevated glioma risk at the highest exposure levels, but potential bias prevented a causal interpretation $[41,43]$. A re-analysis of Canadian data from the INTERPHONE study showed significant results for glioma; comparing the quartile with the highest MP use to those who were not regular users [odds ratio: 2.2 (95\% limits: 1.3, 4.1)]. Unlike the Canadian statistics, the INTERPHONE multinational data showed a significantly diminished risk of the studied tumors in the majority of MP users, while a modest risk elevation was found only in the top decile of the cumulative MP use [44, 45].

If the carcinogenic effects of EMF from MPs were substantial, the corresponding incidence rates would have been higher; especially in more developed countries. However, the incidence of glioma in the US remained stable between1992-2008 in spite of the great increase in the MP use [46, 47]. According 
to the IARC, there has been no substantial increase in brain tumor incidence rates since the beginning of the MP era [9]. According to the International Commission for Non-Ionizing Radiation Protection (ICNIRP) and Scientific Committee on Emerging and Newly Identified Health Risks (SCENIHR), the trend in the accumulating evidence is against the hypothesis that MPs may cause brain tumors $[44,48]$. The most recent review concluded that the current evidence including in vitro, in vivo, and epidemiological studies do not indicate an association between MP use and tumors developing from the most exposed organs and tissues, the brain and salivary glands in particular. Any potentially undetected risk is expected to be small, possibly concerning those using MP for a long period $(>15$ years), rare brain tumor types, and MP usage by children [49]. A moderate increase in the incidence of brain tumors in certain time periods, countries and age groups $[50,51]$ is out of proportion to the tremendous rise in the MP use. Some researchers do not exclude the role of MPs as a cause of this increase and also mention the X-ray exposures from CT scans [50]. It seems to be logical that the registered incidence of brain tumors has increased due to improvements in imaging technology and access to health care units [46, 47, 50-52].

In the INTERPHONE and some other studies, the risk of glioma tended to be higher in individuals who reported the usual MP use on the same side of the head as their tumors [40, 41]. However, the ipsilateral effect found in low exposure groups suggested that patients might have over-reported the use of MPs on the tumor side (recall bias) [41, 43]. Bias is known to occur in the epidemiologic research: the dose-dependent selection and selfselection, observation, participation, recall bias, etc. $[21,49,53]$. At the beginning of the MP era, the use of MPs was associated with a higher income [39], which, in turn, must be associated with better diagnostics. This bias can explain dose-effect relationships in some studies. Admittedly, MPs are affordable today for the majority of people also in developing countries; and it is unclear whether the socioeconomic bias still plays any significant role.

\section{Experimental Studies}

Long-term exposures to EMF have consistently shown no increase in cancer risk in animal experiments $[48,54,55]$. Numerous in vitro studies have been negative as well, while the more research quality criteria were satisfied, the less cellular responses tended to be observed [56, 57]. Reliability of some experimental data is questionable as they report a carcinogenic effect at exposures below the limits for MP, while a clear dose-response effect is absent [58]. The publication bias i.e. preferred publication of positive results is known. As mentioned above, the existing evidence was found not to be sufficient to prove that EMF is directly genotoxic, while some of the reported adverse effects may be attributed to hyperthermia. The supposed combined effect of EMF with carcino- and mutagens need further investigations $[9,13,59,60]$. As discussed in this review, the only thinkable mechanisms are heating and induced electric currents. Biological systems are "noisy" on the molecular level as a consequence of thermal agitation. EMF affects cells or other biological structures if their physical impact overcomes the endogenous noise i.e. thermal motion [61].

Certain experimental results on the molecular and cellular levels are important but their significance for the pathogenesis of human diseases remains uncertain. Considering the adaptation of living organisms to EMF, it is not enough to demonstrate an alteration mechanism on a molecular level to document a damaging effect as there may be permanently functioning mechanisms of repair and compensation. The same has been discussed for ionizing radiation, where DNA damage and repair are in dynamic equilibrium at exposure levels comparable to the natural radiation background [1]. Of considerable interest are the results by Ketabi et al., [62] and Mohammadzadeh et al., [63] on the frequency dependent influence of EMF on the ion channels in artificial membranes and the OmpF channel-forming protein. The questions, however, remain how efficient is this impact on the in vivo counteractions and what implications has the EMF influence on cell membranes for the hydration state of cells and pathogenesis of diseases. In particular, the assumption that "EMF at $930 \mathrm{MHz}$ probably induces a specific conformation in the protein through changes in the structure of surrounding water molecules" [62] needs an experimental confirmation in protein solutions. Further studies are obviously needed.

Existing experimental findings cannot provide an explanation for supposed carcinogenicity of EMF, while no established biological or biophysical 
mechanisms are known [44, 54, 57, 58]. Large-scale animal experiments could provide more information, for example, studies within the framework of the National Toxicology Program (NTP) in the US. The recent NTP report suggested that a lifetime intermittent exposure to CDMA (Code Division Multiple Access) or GSM (Global System for Mobile communication) $900 \mathrm{MHz}$ signals at a whole-body average SAR of $1.5-6 \mathrm{~W} / \mathrm{kg} 18 \mathrm{~h} /$ day increased the incidence of gliomas in the brain and schwannomas of the heart in male rats, but not females [64, 65]. The tumors did not shorten the average lifespan. The life duration in almost all study groups of males and in some groups of females was longer in controls, which is compatible with hormesis. The life duration is obviously more important than the incidence of particular age-associated tumors that have no impact on the average lifespan. Furthermore, it was noticed that neither glial cell hyperplasia nor heart schwannomas were observed in control rats [66]. Note that the histological evaluation of glial hyperplasia may be not free from subjectivity. A statistically significant increase in the incidence of heart schwannoma was observed in EMF-treated male rats in a recent study [67]. The cause of the differences between the study and control groups could have been temperature-induced metabolic changes due to a slight (usually $<1^{\circ} \mathrm{C}$ ) but a prolonged elevation of the body temperature in many exposed rats [49]. This assumption agrees with the negative results of NTP carcinogenesis studies in mice [68], which are less sensitive to EMF-induced increase in body temperature [69]. The more pronounced effect in male rats $[64,65,67]$ may be due to being larger than females and higher sensitivity of male rats to EMF-induced heating [69]. Moreover, the absence of a significant increase in the body temperature does not disprove the local heating $[64,65]$ with hot spots caused by local tissue properties and wave interference e.g. in motionless, sleeping animals. In any case, the exposure time (9-19 h/day) in the experiments $[64,65,67]$ was incomparably higher than in MP users.

\section{UHF Therapy in Head and Neck Area}

Supposed risks discussed above are induced by EMF of non-thermal intensity i.e. with a negligible elevation of the tissue temperatures. At the same time, the ultra-high frequency (UHF) therapy of thermal intensity has been widely used and officially recommended in the former Soviet Union (fSU) for the treatment of inflammatory otorhinolaryngological and other conditions in children and adults since the 1960s [70-74]. The output power of UHF devices applied to the head and neck area has been 15$30 \mathrm{~W}$ [71]. The extremely high-frequency (EHF) fields have also been used for respiratory and allergic conditions in children, while the absence of contraindications was pointed out [70]. Associations of the UHF therapy with brain or other tumors have never been reported, although brain and eye tissues may suffer if certain power levels are exceeded [75]. Considering the anatomical proximity of tonsils, nasal cavity, eyes and the brain; especially in children, there have been concerns about such use of microwaves [72]. Experiments with large animals e.g. calves, imitating UHF-therapy, might be helpful to evaluate adverse effects, including those from imprecise focusing and excessive exposures that may occur in the routine practice.

The UHF therapy (5-12 procedures lasting for a period of 5-15 min for each procedure) [71] can be regarded as a subacute exposure, while the total absorbed energy in MP users may be higher. However, in view of the lacking verification of any non-thermal damaging mechanism, established knowledge does not suggest accumulation EMF effects with time [48]. Lifetime studies of EMFexposed animals have shown no cumulative adverse effects in their endocrine, hematological, or immune systems. Cardiovascular system and blood pressure regulation are not affected in the absence of significant heating or electric currents [22]. No correlations between the in vitro exposure duration and cellular responses have been found [57]. The epidemiological data have been, however, controversial. People using MP for a long period ( $\geq 10$ years) and accumulating the highest lifetime doses, might be expected to have the highest risk. This was found by the INTERPHONE study neither for glioma nor for meningioma [41]. In other studies, the risk of glioma increased with the increasing application time since the first MP use or with increasing cumulative call time [27, 29, 35]. Considering potential bias in the epidemiological research, cumulative effects should be tested by large-scale animal experiments. Analogously to the infrared radiation, no plausible mechanisms of the supposed accumulation of non-thermal EMF effects are known. Some kinds of thermal damage can, however, accumulate e.g. decreasing lens 
transparency.

Being a component of the natural environment, EMF may affect living organisms like the weather does, not necessarily causing harm. Theoretically, EMF may influence the nervous system, where moving electrical potentials participate. Transient effects on neural functions or retinal phosphenes are not considered to be adverse health effects, although they may be disturbing [76]. The same can be said about the possible associations between EMF and tinnitus which has not been well established [77]. Results of a meta-analysis suggested that EMF may have a slight impact on human attention and working memory $[78,79]$, although there is an opinion that such effects are unproven $[76,80]$. Improvement of cognition and other positive effects of transcranial magnetic and direct current stimulation have been also reported [81-83], which is beyond the scope of this review.

There have been reports from the fSU on the non-thermal effects of EMF on neural, immune, endocrine, and reproductive functions [84-88]. Stricter regulations limiting professional exposures to EMF in the fSU than in the US have been partly based on such reports [89]. Admittedly, some results could not be reproduced [90-92]. Certain experiments have been doubtful, for example, irradiation of eggs in an incubator by a static MP resulted in increased embryonic mortality. So, concerns were raised in terms of EMF impact on human embryos and newborn infants [25]. It was not taken into account that chicken embryos in an incubator are static and thermally insulated, being at the same time very vulnerable to heat [93]. The temperature inside eggs may be elevated with damaged hot spots.

\section{CONCLUSION}

In conclusion, there is neither compelling evidence nor theoretic plausibility of cause-effect relationships between exposures to EMF and cancer. Certainly, epidemiological studies cannot be dismissed; but more attention should be given to potential systematic errors and bias. Large samples and statistical precision do not protect against bias [94]. To confirm a cause-effect relationship, verification by reliable methods and understanding of mechanisms are generally needed [95]. Robust evidence could be obtained from large-scale animal experiments. The main problem with experiments of rare outcomes is the difficulty to achieve statistical significance due to a limited number of animals. To make experiments less expensive, it is unnecessary to examine the health conditions of each animal, perform necropsies or look for certain malignancies [55]. It would suffice to maintain large numbers of animals and register the life duration in equal conditions [96]. The life span is known to be a sensitive attributable endpoint to radiation exposures. In the NTP experiments discussed above $[64,65]$, the life duration was longer in exposed animal groups than in controls, which may reflect the net benefit in accordance with hormesis. The net benefit or harm reflected in the life duration is obviously more important than the incidence of certain age-related tumors. As for the regulations, strict observation of realistic safety norms is more helpful than excessive restrictions for public health.

\section{ACKNOWLEDGMENTS}

Not applicable.

\section{CONFLICT OF INTEREST}

The authors declared no conflict of interest.

\section{ETHICS APPROVAL}

Not applicable.

\section{REFERENCES}

1. Jargin SV. Hormesis and radiation safety norms: Comments for an update. Hum Exp Toxicol. 2018;37(11):123343. DOI: $10.1177 / 0960327118765332$ PMID: 29607734.

2. Mattson MP, Calabrese EJ. Hormesis. A Revolution in Biology, Toxicology and Medicine. New York: Springer; 2010.

3. Anderson D, Fuller-Rowell T. The ionosphere. Boulder, CO: Space Environment Center; 1999.

4. Kholodov Iu A. [The body and magnetic fields]. Usp Fiziol Nauk. 1982;13(2):48-64. PMID: 6178230.

5. Tsybulin O, Sidorik E, Kyrylenko S, Henshel D, Yakymenko I. GSM $900 \mathrm{MHz}$ microwave radiation affects embryo development of Japanese quails. Electromagn Biol Med. 2012;31(1):75-86. DOI: 10.3109/15368378.2011.624656 PMID: 22268787.

6. Sun C, Wei X, Fei Y, Su L, Zhao X, Chen G, et al. Mobile phone signal exposure triggers a hormesis-like effect in $\operatorname{Atm}(+/+)$ and Atm(-/-) mouse embryonic fibroblasts. Sci Rep. 2016;6:37423. DOI: 10.1038/srep37423 PMID: 27857169.

7. Perez FP, Zhou X, Morisaki J, Jurivich D. Electromagnetic field therapy delays cellular senescence and death by enhancement of the heat shock response. Exp Gerontol. 2008;43(4):307-16. DOI: 10.1016/j.exger.2008.01.004 PMID: 18325704.

8. Stuchly MA. Interaction of radiofrequency and microwave 
radiation with living systems. A review of mechanisms. Radiat Environ Biophys. 1979;16(1):1-14. PMID: 382232

9. International Agency for Research on Cancer. IARC Monographs on the Evaluation of Carcinogenic Risks to Humans. Non-ionizing radiation, Part 1: static and extremely low-frequency (ELF) electric and magnetic fields. France: WHO, IARC Press; 2013. 1-460s p.

10. Moulin JJ, Wild P, Mantout B, Fournier-Betz M, Mur JM, Smagghe G. Mortality from lung cancer and cardiovascular diseases among stainless-steel producing workers. Cancer Causes Control. 1993;4(2):75-81. PMID: 8386949.

11. Tenkanen L, Hakulinen T, Hakama M, Saxen E. Sauna, dust and migration as risk factors in lung cancer among smoking and non-smoking males in Finland. Int J Cancer. 1985;35(5):637-42. PMID: 3997283.

12. Bunin GR, Robison LL, Biegel JA, Pollack IF, Rorke-Adams LB. Parental heat exposure and risk of childhood brain tumor: a Children's Oncology Group study. Am J Epidemiol. 2006;164(3):222-31. DOI: 10.1093/aje/kwj174 PMID: 16775044 .

13. Verschaeve L, Juutilainen J, Lagroye I, Miyakoshi J, Saunders $\mathrm{R}$, de Seze R, et al. In vitro and in vivo genotoxicity of radiofrequency fields. Mutat Res. 2010;705(3):252-68. DOI: 10.1016/j.mrrev.2010.10.001 PMID: 20955816.

14. Chauhan P, Verma HN, Sisodia R, Kesari KK. Microwave radiation $(2.45 \mathrm{GHz})$-induced oxidative stress: Whole-body exposure effect on histopathology of Wistar rats. Electromagn Biol Med. 2017;36(1):20-30. DOI: 10.3109/15368378.2016.1144063 PMID: 27362544.

15. El-Helaly M, Abu-Hashem E. Oxidative stress, melatonin level, and sleep insufficiency among electronic equipment repairers. Indian J Occup Environ Med. 2010;14(3):66-70. DOI: $10.4103 / 0019-5278.75692$ PMID: 21461157.

16. Mortazavi SM, Mortazavi SA. Oxidative mechanisms of biological activity of low-intensity radiofrequency radiation. Electromagn Biol Med. 2016;35(4):303-4. DOI: 10.3109/15368378.2016.1138125 PMID: 27232546.

17. Jargin SV. On the use of carnosine and antioxidants: A letter from Russia. J Intercult Ethnopharmacol. 2016;5(3):317-9. DOI: $10.5455 /$ jice.20160409010229 PMID: 27366359.

18. Giorgio M. Oxidative stress and the unfulfilled promises of antioxidant agents. Ecancermedicalscience. 2015;9:556. DOI: 10.3332/ecancer.2015.556 PMID: 26284120.

19. Samaras T, Kalampaliki E, Sahalos JN. Influence of thermophysiological parameters on the calculations of temperature rise in the head of mobile phone users. IEEE Trans Electromagn Compat. 2007;49(4):936-9.

20. Hirata A, Shirai K, Fujiwara O. On averaging mass of SAR correlating with temperature elevation due to a dipole antenna. Prog Electromagn Res. 2008;84:221-37. DOI: 10.2528/PIER08072704.

21. National Cancer Institute. Cell Phones and Cancer Risk. Bethesda, MD: NIH; 2017 [updated 2019 January 09; cited 2019 April 09]. Available from: https://www.cancer. gov/about-cancer/causes-prevention/risk/radiation/cellphones-fact-sheet.

22. Black DR, Heynick LN. Radiofrequency (RF) effects on blood cells, cardiac, endocrine, and immunological functions. Bioelectromagnetics. 2003;Suppl 6:S187-95. DOI: 10.1002/bem.10166 PMID: 14628314.

23. Foster KR, Glaser R. Thermal mechanisms of interaction of radiofrequency energy with biological systems with relevance to exposure guidelines. Health Phys. 2007;92(6):60920. DOI: 10.1097/01.HP.0000262572.64418.38 PMID: 17495663.

24. McIntosh RL, Anderson V. SAR versus S(inc): What is the appropriate RF exposure metric in the range 1-10 GHz? Part II: Using complex human body models. Bioelectromagnetics. 2010;31(6):467-78. DOI: 10.1002/bem.20574 PMID: 20354998.

25. Grigor YG, Samoylov AS, Bushmanov A, Horseva NI. Cellular connection and the health of children - problem of the third millennium. Med Radiol Radiat Saf. 2018;62(2):3946. DOI: 10.12737/article_58f0b9573b6b59.54629416.

26. Baan R, Grosse Y, Lauby-Secretan B, El Ghissassi F, Bouvard V, Benbrahim-Tallaa L, et al. Carcinogenicity of radiofrequency electromagnetic fields. Lancet Oncol. 2011;12(7):624-6. PMID: 21845765.

27. Morgan LL, Miller AB, Sasco A, Davis DL. Mobile phone radiation causes brain tumors and should be classified as a probable human carcinogen (2A) (review). Int J Oncol. 2015;46(5):1865-71. DOI: 10.3892/ijo.2015.2908 PMID: 25738972.

28. Hardell L, Carlberg M, Hansson Mild K. Use of mobile phones and cordless phones is associated with increased risk for glioma and acoustic neuroma. Pathophysiology. 2013;20(2):85-110. DOI: 10.1016/j.pathophys.2012.11.001 PMID: 23261330.

29. Hardell L, Carlberg M, Soderqvist F, Mild KH. Case-control study of the association between malignant brain tumours diagnosed between 2007 and 2009 and mobile and cordless phone use. Int J Oncol. 2013;43(6):1833-45. DOI: 10.3892/ijo.2013.2111 PMID: 24064953.

30. Hardell L, Carlberg M, Hansson Mild K. Pooled analysis of case-control studies on malignant brain tumours and the use of mobile and cordless phones including living and deceased subjects. Int J Oncol. 2011;38(5):1465-74. DOI: 10.3892/ijo.2011.947 PMID: 21331446.

31. Yang L, Hao D, Wang M, Zeng Y, Wu S, Zeng Y. Cellular neoplastic transformation induced by $916 \mathrm{MHz}$ microwave radiation. Cell Mol Neurobiol. 2012;32(6):1039-46. DOI: 10.1007/s10571-012-9821-7 PMID: 22395787.

32. Soderqvist F, Carlberg M, Hansson Mild K, Hardell L. Childhood brain tumour risk and its association with wireless phones: a commentary. Environ Health. 2011;10:106. DOI: 10.1186/1476-069X-10-106 PMID: 22182218.

33. Davis DL, Kesari S, Soskolne CL, Miller AB, Stein Y. Swedish review strengthens grounds for concluding that radiation from cellular and cordless phones is a probable human carcinogen. Pathophysiology. 2013;20(2):123-9. DOI: 10.1016/j.pathophys.2013.03.001 PMID: 23664410.

34. Carpenter DO. Electromagnetic fields and cancer: the cost of doing nothing. Rev Environ Health. 2010;25(1):75-80. PMID: 20429163.

35. Carlberg M, Hardell L. Evaluation of Mobile Phone and 
Cordless Phone Use and Glioma Risk Using the Bradford Hill Viewpoints from 1965 on Association or Causation. Biomed Res Int. 2017;2017:9218486. DOI: 10.1155/2017/9218486 PMID: 28401165.

36. Bhargav H, Srinivasan TM, Varambally S, Gangadhar BN, Koka P. Effect of Mobile Phone-Induced Electromagnetic Field on Brain Hemodynamics and Human Stem Cell Functioning: Possible Mechanistic Link to Cancer Risk and Early Diagnostic Value of Electronphotonic Imaging. J Stem Cells. 2015;10(4):287-94. DOI: jsc.2015.10.4.287 PMID: 27144830.

37. Yoon S, Choi JW, Lee E, An H, Choi HD, Kim N. Mobile phone use and risk of glioma: a case-control study in Korea for 2002-2007. Environ Health Toxicol. 2015;30:e2015015. DOI: 10.5620/eht.e2015015 PMID: 26726040.

38. Muscat JE, Malkin MG, Thompson S, Shore RE, Stellman $\mathrm{SD}, \mathrm{McRee} \mathrm{D}$, et al. Handheld cellular telephone use and risk of brain cancer. JAMA. 2000;284(23):3001-7. PMID: $\underline{11122586 .}$.

39. Schuz J, Jacobsen R, Olsen JH, Boice JD, Jr., McLaughlin JK, Johansen C. Cellular telephone use and cancer risk: update of a nationwide Danish cohort. J Natl Cancer Inst. 2006;98(23):1707-13. DOI: 10.1093/jnci/djj464 PMID: $\underline{17148772 .}$

40. Inskip PD, Tarone RE, Hatch EE, Wilcosky TC, Shapiro WR, Selker RG, et al. Cellular-telephone use and brain tumors. N Engl J Med. 2001;344(2):79-86. DOI: 10.1056/ NEJM200101113440201 PMID: 11150357.

41. Group IS. Brain tumour risk in relation to mobile telephone use: results of the INTERPHONE international casecontrol study. Int J Epidemiol. 2010;39(3):675-94. DOI: 10.1093/ije/dyq079 PMID: 20483835.

42. Alexiou GA, Sioka C. Mobile phone use and risk for intracranial tumors. J Negat Results Biomed. 2015;14:23. DOI: 10.1186/s12952-015-0043-7 PMID: 26699288.

43. Grell K, Frederiksen K, Schuz J, Cardis E, Armstrong B, Siemiatycki J, et al. The Intracranial Distribution of Gliomas in Relation to Exposure From Mobile Phones: Analyses From the INTERPHONE Study. Am J Epidemiol. 2016;184(11):818-28. DOI: 10.1093/aje/kww082 PMID: 27810856.

44. Swerdlow AJ, Feychting M, Green AC, Leeka Kheifets LK, Savitz DA, International Commission for Non-Ionizing Radiation Protection Standing Committee on Epidemiology. Mobile phones, brain tumors, and the interphone study: where are we now? Environ Health Perspect. 2011;119(11):1534-8. DOI: 10.1289/ehp.1103693 PMID: 22171384.

45. Momoli F, Siemiatycki J, McBride ML, Parent ME, Richardson L, Bedard D, et al. Probabilistic Multiple-Bias Modeling Applied to the Canadian Data From the Interphone Study of Mobile Phone Use and Risk of Glioma, Meningioma, Acoustic Neuroma, and Parotid Gland Tumors. Am J Epidemiol. 2017;186(7):885-93. DOI: 10.1093/aje/ kwx157 PMID: 28535174.

46. Inskip PD, Hoover RN, Devesa SS. Brain cancer incidence trends in relation to cellular telephone use in the United States. Neuro Oncol. 2010;12(11):1147-51. DOI: 10.1093/ neuonc/noq077 PMID: 20639214.
47. Little MP, Rajaraman P, Curtis RE, Devesa SS, Inskip PD, Check DP, et al. Mobile phone use and glioma risk: comparison of epidemiological study results with incidence trends in the United States. BMJ. 2012;344:e1147. DOI: 10.1136/bmj.e1147 PMID: 22403263.

48. Scientific Committee on Emerging Newly Identified Health Risks. Opinion on potential health effects of exposure to electromagnetic fields. Bioelectromagnetics. 2015;36(6):480-4. DOI: 10.1002/bem.21930 PMID: 26179386.

49. Roosli M, Lagorio S, Schoemaker MJ, Schuz J, Feychting M. Brain and Salivary Gland Tumors and Mobile Phone Use: Evaluating the Evidence from Various Epidemiological Study Designs. Annu Rev Public Health. 2019;40:22138. DOI: 10.1146/annurev-publhealth-040218-044037 PMID: 30633716.

50. Alasdair P, Denis L. H, Lamburn G, Carroll MJ. Brain Tumours: Rise in Glioblastoma Multiforme Incidence in England 1995-2015 Suggests an Adverse Environmental or Lifestyle Factor. J Environ Public Health. 2018;2018:7910754. DOI: 10.1155/2018/7910754.

51. Gittleman HR, Ostrom QT, Rouse CD, Dowling JA, de Blank PM, Kruchko CA, et al. Trends in central nervous system tumor incidence relative to other common cancers in adults, adolescents, and children in the United States, 2000 to 2010. Cancer. 2015;121(1):102-12. DOI: $10.1002 /$ cncr.29015 PMID: 25155924.

52. Ostrom QT, Bauchet L, Davis FG, Deltour I, Fisher JL, Langer CE, et al. The epidemiology of glioma in adults: a "state of the science" review. Neuro Oncol. 2014;16(7):896913. DOI: 10.1093/neuonc/nou087 PMID: 24842956.

53. Vrijheid M, Deltour I, Krewski D, Sanchez M, Cardis E. The effects of recall errors and of selection bias in epidemiologic studies of mobile phone use and cancer risk. J Expo Sci Environ Epidemiol. 2006;16(4):371-84. DOI: 10.1038/ si.jes. 7500509 PMID: 16773122 .

54. Meena JK, Verma A, Kohli C, Ingle GK. Mobile phone use and possible cancer risk: Current perspectives in India. Indian J Occup Environ Med. 2016;20(1):5-9. DOI: 10.4103/0019-5278.183827 PMID: 27390472.

55. Sienkiewicz Z, Calderon C, Broom KA, Addison D, Gavard A, Lundberg L, et al. Are Exposures to Multiple Frequencies the Key to Future Radiofrequency Research? Front Public Health. 2017;5:328. DOI: 10.3389/ fpubh.2017.00328 PMID: 29276705.

56. Vijayalaxmi, Prihoda TJ. Comprehensive Review of Quality of Publications and Meta-analysis of Genetic Damage in Mammalian Cells Exposed to Non-Ionizing Radiofrequency Fields. Radiat Res. 2019;191(1):20-30. DOI: 10.1667/ RR15117.1 PMID: 30339042.

57. Simko M, Remondini D, Zeni O, Scarfi MR. Quality Matters: Systematic Analysis of Endpoints Related to "Cellular Life" in Vitro Data of Radiofrequency Electromagnetic Field Exposure. Int J Environ Res Public Health. 2016;13(7). DOI: 10.3390/ijerph13070701 PMID: 27420084.

58. Lerchl A, Klose M, Grote K, Wilhelm AF, Spathmann O, Fiedler T, et al. Tumor promotion by exposure to radiofre- 
quency electromagnetic fields below exposure limits for humans. Biochem Biophys Res Commun. 2015;459(4):58590. DOI: 10.1016/j.bbrc.2015.02.151 PMID: 25749340.

59. Verschaeve L. Genetic effects of radiofrequency radiation (RFR). Toxicol Appl Pharmacol. 2005;207(2 Suppl):336-41. DOI: 10.1016/j.taap.2005.03.028 PMID: $\underline{16019045 .}$.

60. Tillmann T, Ernst H, Streckert J, Zhou Y, Taugner F, Hansen $\mathrm{V}$, et al. Indication of cocarcinogenic potential of chronic UMTS-modulated radiofrequency exposure in an ethylnitrosourea mouse model. Int J Radiat Biol. 2010;86(7):529 41. DOI: $10.3109 / 09553001003734501$ PMID: 20545575.

61. Adair RK. Biophysical limits on athermal effects of RF and microwave radiation. Bioelectromagnetics. 2003;24(1):3948. DOI: $10.1002 /$ bem. 10061 PMID: 12483664.

62. Ketabi N, Mobasheri H, Faraji-Dana R. Electromagnetic fields (UHF) increase voltage sensitivity of membrane ion channels; possible indication of cell phone effect on living cells. Electromagn Biol Med. 2015;34(1):1-13. DOI: 10.3109/15368378.2013.844706 PMID: 24236537.

63. Mohammadzadeh M, Mobasheri H, Arazm F. Electromagnetic field (EMF) effects on channel activity of nanopore OmpF protein. Eur Biophys J. 2009;38(8):1069-78. DOI: 10.1007/s00249-009-0511-4 PMID: 19603160.

64. National Toxicology Program. Toxicology and Carcinogenesis Studies in B6C3F1/N Mice Exposed to WholeBody Radio Frequency Radiation at a Frequency $(1,900$ $\mathrm{MHz}$ ) and Modulations (GSM and CDMA) Used by Cell Phones. Technical Report. USA: Public Health Service, Department of Health and Human Services; 2018 November. Report No.: NTP TR 596.

65. National Toxicology Program. Toxicology and carcinogenesis studies in Hsd: Sprague Dawley sd rats exposed to whole-body radio frequency radiation at a frequency ( 900 $\mathrm{MHz}$ ) and modulations (GSM and CDMA) used by cell phones. Technical Report. USA: Public Health Service, Department of Health and Human Services; 2018 November. Report No.: NTP TR 595.

66. Melnick RL. Commentary on the utility of the National Toxicology Program study on cell phone radiofrequency radiation data for assessing human health risks despite unfounded criticisms aimed at minimizing the findings of adverse health effects. Environ Res. 2019;168:1-6. DOI: 10.1016/j.envres.2018.09.010 PMID: 30243215.

67. Falcioni L, Bua L, Tibaldi E, Lauriola M, De Angelis L, Gnudi F, et al. Report of final results regarding brain and heart tumors in Sprague-Dawley rats exposed from prenatal life until natural death to mobile phone radiofrequency field representative of a $1.8 \mathrm{GHz}$ GSM base station environmental emission. Environ Res. 2018;165:496-503. DOI: 10.1016/j.envres.2018.01.037 PMID: 29530389.

68. National Toxicology Program. Toxicology and Carcinogenesis Studies of 60-HZ Magnetic Fields IN F344/N Rats and B6C3F1 Mice (Whole-body Exposure Studies). Technical Report. USA: Public Health Service, Department of Health and Human Services; 1999 Apr. Report No.: NTP TR 488 Contract No.: NIH Publication No. 99-3978.

69. Wyde ME, Horn TL, Capstick MH, Ladbury JM, Koepke
G, Wilson PF, et al. Effect of cell phone radiofrequency radiation on body temperature in rodents: Pilot studies of the National Toxicology Program's reverberation chamber exposure system. Bioelectromagnetics. 2018;39(3):190-9. DOI: 10.1002/bem.22116 PMID: 29537695.

70. Povazhnaia EL, Mambetalieva AS. [Extremely high frequency therapy for the prevention of acute respiratory diseases in children with chronic ENT and allergic diseases]. Vopr Kurortol Fizioter Lech Fiz Kult. 2010(5):17-21. PMID: 21332086.

71. Antropova MI, Dolin Iu S, Krylov OA, Shereshevskii OV. [UHF Therapy. Large Medical Encyclopedia]. Moscow: Soviet Encyclopedia. 1985;25:483-4.

72. Jargin S. Mobile phones: carcinogenic and other potential risks. J Environ Occup Sci. 2017;6:58-60.

73. Nikolaevskaia V. [Microwave therapy of ear, nose and throat diseases. Methodical letter]. Health Ministry of RSFSR, Moscow. 1966.

74. Nikolaevskaia VP. [The use of microwave therapy in patients with chronic tonsillitis]. Vestn Otorinolaringol. 1966;28(6):31-4. PMID: 6003815.

75. Leitgeb N, Omerspahic A, Niedermayr F. Exposure of non-target tissues in medical diathermy. Bioelectromagnetics. 2010;31(1):12-9. DOI: 10.1002/bem.20521 PMID: 19711373.

76. International Commission on Non-Ionizing Radiation Protection. Guidelines for limiting exposure to time-varying electric and magnetic fields ( $1 \mathrm{~Hz}$ to $100 \mathrm{kHz}$ ). Health Phys. 2010;99(6):818-36. DOI: 10.1097/HP.0b013e3181f06c86 PMID: 21068601.

77. Medeiros LN, Sanchez TG. Tinnitus and cell phones: the role of electromagnetic radiofrequency radiation. Braz J Otorhinolaryngol. 2016;82(1):97-104. DOI: 10.1016/j. bjorl.2015.04.013 PMID: 26602000.

78. Barth A, Winker R, Ponocny-Seliger E, Mayrhofer W, Ponocny I, Sauter C, et al. A meta-analysis for neurobehavioural effects due to electromagnetic field exposure emitted by GSM mobile phones. Occup Environ Med. 2008;65(5):342-6. DOI: 10.1136/oem.2006.031450 PMID: 17928386.

79. Regel SJ, Achermann P. Cognitive performance measures in bioelectromagnetic research--critical evaluation and recommendations. Environ Health. 2011;10(1):10. DOI: 10.1186/1476-069X-10-10 PMID: 21266038.

80. Valentini E, Ferrara M, Presaghi F, De Gennaro L, Curcio G. Systematic review and meta-analysis of psychomotor effects of mobile phone electromagnetic fields. Occup Environ Med. 2010;67(10):708-16. DOI: 10.1136/ oem.2009.047027 PMID: 20837651.

81. Mutz J, Vipulananthan V, Carter B, Hurlemann R, Fu CHY, Young AH. Comparative efficacy and acceptability of nonsurgical brain stimulation for the acute treatment of major depressive episodes in adults: systematic review and network meta-analysis. BMJ. 2019;364:11079. DOI: 10.1136/ bmj.11079 PMID: 30917990.

82. Chervyakov AV, Chernyavsky AY, Sinitsyn DO, Piradov MA. Possible Mechanisms Underlying the Therapeutic Effects of Transcranial Magnetic Stimulation. Front Hum 
Neurosci. 2015;9:303. DOI: 10.3389/fnhum.2015.00303 PMID: 26136672.

83. McKinley RA, Bridges N, Walters CM, Nelson J. Modulating the brain at work using noninvasive transcranial stimulation. Neuroimage. 2012;59(1):129-37. DOI: 10.1016/j. neuroimage.2011.07.075 PMID: 21840408.

84. Shandala MG. [Physical Environmental Fectors in the Ecology of the Brain]. Gig Sanit. 2015;94(3):10-4. PMID: $\underline{26302550 .}$.

85. Shandala MG. [Experience in a hygienic assessment of problems related to physical environmental factors]. Gig Sanit. 1999(4):3-9. PMID: 10465864.

86. Pal'tsev Iu P, Pokhodzei LV, Rubtsova NB, Bogacheva EV. [Problems of harmonization of sanitary regulations of the electromagnetic fields of mobile radio communication equipment]. Gig Sanit. 2013(3):39-42. PMID: 24340578.

87. Belyaev IY, Grigoriev YG. Problems in assessment of risks from exposures to microwaves of mobile communication. Radiats Biol Radioecol. 2007;47(6):727-32. PMID: 18380333.

88. Grigor YG. From Electromagnetic Smog to Electromagnetic Chaos. To Evaluating the Hazards of Mobile Communication for Health of the Population. Med Radiol Radiat Saf. 2018;63(3):28-33. DOI: 10.12737/article 5b168a752 d92b1.01176625.

89. Repacholi M, Grigoriev Y, Buschmann J, Pioli C. Scientific basis for the Soviet and Russian radiofrequency standards for the general public. Bioelectromagnetics. 2012;33(8):623-33. DOI: 10.1002/bem.21742 PMID: 22753071.

90. Repacholi M, Buschmann J, Pioli C, Sypniewska R, International Oversight Committee members for the FrancoRussian P. An international project to confirm Soviet-era results on immunological and teratological effects of RF field exposure in Wistar rats and comments on Grigoriev et al. [2010]. Bioelectromagnetics. 2011;32(4):325-30. DOI: 10.1002/bem.20638 PMID: 21452363.

91. Mitchell CL, McRee DI, Peterson NJ, Tilson HA, Shandala MG, Rudnev MI, et al. Results of a United States and Soviet Union joint project on nervous system effects of microwave radiation. Environ Health Perspect. 1989;81:2019. DOI: $10.1289 /$ ehp.8981201 PMID: 2527152.

92. McRee DI. Review of Soviet/Eastern European research on health aspects of microwave radiation. Bull N Y Acad Med. 1979;55(11):1133-51. PMID: 295246.

93. Nakage ES, Cardozo JP, Pereira GT, Queiroz SA, Boleli IC. Effect of temperature on incubation period, embryonic mortality, hatch rate, egg water loss and partridge chick weight (Rhynchotus rufescens). Rev Bras Cienc Avic. 2003;5(2):131-5. DOI: 10.1590/S1516635X2003000200007.

94. Richardson DB, Cardis E, Daniels RD, Gillies M, O'Hagan JA, Hamra GB, et al. Risk of cancer from occupational exposure to ionising radiation: retrospective cohort study of workers in France, the United Kingdom, and the United States (INWORKS). BMJ. 2015;351:h5359. DOI: $10.1136 /$ bmj.h5359 PMID: 26487649.

95. Dourson M, Becker RA, Haber LT, Pottenger LH, Bredfeldt T, Fenner-Crisp PA. Advancing human health risk assessment: integrating recent advisory committee recommendations. Crit Rev Toxicol. 2013;43(6):467-92. DOI: 10.3109/10408444.2013.807223 PMID: 23844697.

96. Jargin SV. Studies of radiation risk at low doses and low dose rates: a new approach needed. Int J Radiat Biol. 2018:1-2. DOI: 10.1080/09553002.2019.1524991 PMID: 30273088. 